\title{
Vitiligo as a consequence of the use of diphencyprone in the treatment of alopecia areata
}

\author{
Maria Victória Quaresma ${ }^{1 *}$, Thalyta Valle de Rezende ${ }^{2}$, Camille Maximiliana Maia ${ }^{3}$, Bárbara C Poggi ${ }^{4}$ Patrícia Paludo ${ }^{1}$ and Paulo Luzio ${ }^{1}$ \\ ${ }^{1}$ Department of Dermatology, Professor Rubem David Azulay Institute of Dermatology, Rio de Janeiro, Brazil \\ ${ }^{2}$ University of Ribeirão Preto (UNAERP), São Paulo, Brazil \\ ${ }^{3}$ São Paulo Public Employees State Hospital, São Paulo, Brazil \\ ${ }^{4}$ University of Mogi das Cruzes, São Paulo, Brazil
}

\begin{abstract}
Diphencyprone (DCP) is a contact sensitizer that is used to treat dermatological disorders with an immunological origin, such as extensive alopecia areata (AA). Vitiligo is a rare but known side effect of DPC therapy and could be developed as a side effect of DCP therapy at the treatment site or at remote areas. As the development of vitiligo by DCP is unpredictable and the depigmentation may persist indefinitely, it is important to inform all patients about this potential adverse effect before starting DCP. We report herein, a case of vitiligo that was induced by DCP prescribed to treat AA totalis. AA and vitiligo share many susceptibility genes and follicular melanocyte destruction may represent the link between these two conditions.
\end{abstract}

\section{Introduction}

Alopecia areata (AA) is an inflammatory non-scarring hair loss that affects the anagen-stage hair follicles. It is postulated to be induced by an autoimmune process and is characterized histologically by periand intra-follicular infiltration of CD4+ and CD8+ T cells [1]. Genetic factors such as HLA typing, thyroid antibodies, and autoimmune diseases have been associated with subtypes of AA [2].

The worldwide prevalence of vitiligo ranges between 0.5 and $2 \%$. Vitiligo is a multifactorial disease which affects young or adult individuals, it may be associated with other autoimmune diseases such as thyroiditis and AA [3]. Probably, a genetically predisposed vulnerability of melanocytes in the context of an autoimmune diathesis leads to progressive immune destruction of melanocytes [4]. There is experimental evidence that melanocytotoxic chemicals, especially phenolic/catecholic derivatives, could also induce vitiligo $[5,6]$.

The management of AA varies widely among dermatologists. Treatment modalities include corticosteroids, topical irritants, photochemotherapy (PUVA) and contact immunotherapy [2]. Diphencyprone (DCP) is a contact, well tolerated sensitizer, used to treat dermatological conditions resulting from an altered immunological state, such as extensive AA. Adverse effects include local eczema with blistering, regional lymphadenopathy and contact urticaria. Rare adverse effects include an erythema multiform-like reaction, hyperpigmentation, hypopigmentation and vitiligo [7]. We report a case of DCP-induced vitiligo in a patient with history of AA.

\section{Case report}

A 65-year-old Caucasian woman with no personal or familial history of other autoimmune disorders and a 30 years history of hair loss on the whole scalp, was diagnosed as having AA totalis 2 years before this report. She had been treated with corticosteroids, showing a good response, although a shift to DCP was made due to intolerability to the first drug. Following the classic sensitization regimen, she was started on a $2 \%$ application, followed by the treatment dose of $0.001 \%$ after 2 weeks, and then a weekly dose rise guided by the expected erythema as a result of a contact dermatitis reaction. Initial hair regrowth started after 3 months of topical treatment and after 6 months, when final concentration of $0.05 \%$ weekly was reached, the patient developed significant acute contact eczema and vitiligo patches at her forehead bilaterally (Figures 1 and 2). Thus, application was discontinued and the dermatitis treated with oral steroids and antihistamines. After 6 months, the patient noticed the appearance of vitiligo-like hypopigmented lesions at her face (Figure 3).

\section{Discussion}

Vitiligo and AA are skin disorders characterized by an autoimmune pathogenesis that has not yet been elicited. The mechanism of follicular melanocyte destruction in vitiligo and AA may provide a link between the two diseases. Presumably the pathogenesis of AA involves the destruction of melanocytes of the hair follicle, therefore black hairs fall first, and recovery of the white hair takes place earlier. This probably accounts for the connection between the two diseases that target the immune system towards the melanocyte.

There is currently a wide range of therapeutic possibilities for the management of both diseases. Topical immunotherapy, such as DCP, has been used extensively as a therapeutic approach for many

Correspondence to: Maria Victória Quaresma, Alameda Itu, 1030/ 9B, Jardim Paulista. CEP: 01421-001, São Paulo (SP), Brazil, Tel: +55 11 98963-5115; E-mail: mavi@mavictoria.com.br

This case report comes from a special issue on Hair Diseases

Edited by Lidia Rudnicka

Keywords: vitiligo, diphencyprone, alopecia areata

Received: May 28, 2015; Accepted: July 14, 2015; Published: July 17, 2015 


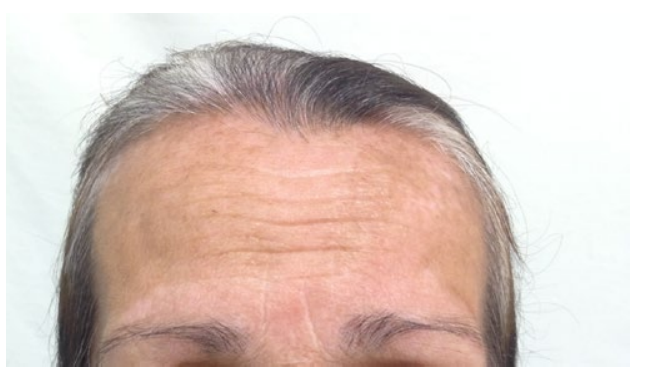

Figure 1. Vitiligo-like hypopigmented lesions over the forehead bilaterally.

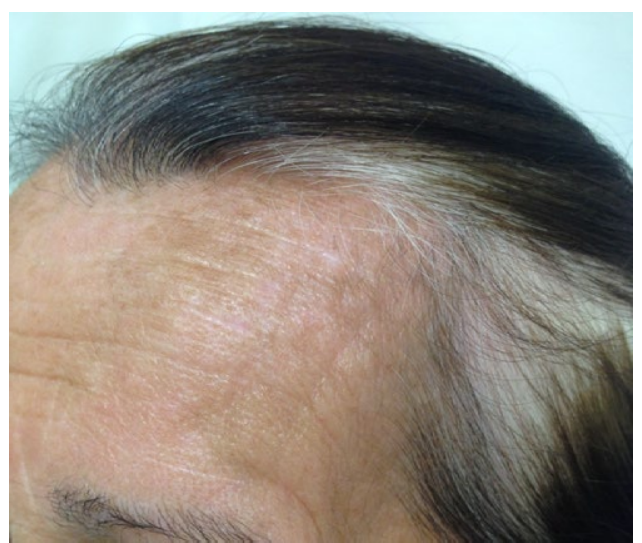

Figure 2. Notice the hypopigmented lesions and the absence of patch alopecia on the scalp.

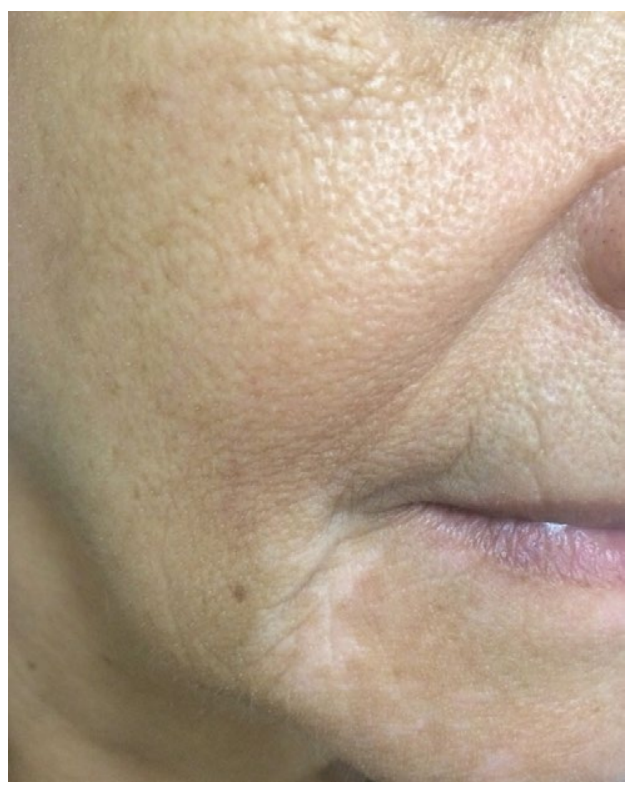

Figure 3. Vitiligo lesions on chin region and distant from the location of diphencyprone application.

dermatological disorders with immunological basis, as AA. DCPinduced vitiligo is a rare, but well documented, adverse event during the treatment for AA [7-9].

There are some hypotheses explaining the relationship of the appearance of vitiligo using DCP. It has been proposed that different $\mathrm{T}$ cells migrate to the treated area with DCP, thus increasing the clearance of the follicular antigen [2]. Presumably when you prescribe the DCP an inflammatory process begins and if the individual has vitiligo in activity (even without clinical manifestation) will generate Koebner phenomenon. Alternatively, it has been postulated that the contact sensitizer may have induced vitiligo through a direct cytotoxic effect on the melanocytes following systemic absorption [7].

As explained, the hypopigmented areas may be the primary course of the disease which is revealed as the result of Koebner phenomenon in suspicious patients of vitiligo or they may be the consequence of direct effect of treatment with DCP on melanocytes (particularly in distant areas) $[8,9]$. In this case, the depigmentation occurred with a relatively low concentration of $0.05 \%$ and after 6 months the hypopigmented lesions did not develop pigmentation and this distinction was not possible.

The management should include discontinuation of DCP and application of topical steroids, also phototherapy, a well-established complementary treatment [10], may also be used in DCP-induced vitiligo. Owing to the unpredictability of the occurrence of this adverse event and the fact that vitiligo might bring an import social burden to a person, it is important to inform all patients about this potential adverse effect before starting the treatment.

\section{References}

1. Herbst V, Zöller M, Kissling S, Wenzel E, Stutz N, et al. (2006) Diphenylcyclopropenone treatment of alopecia areata induces apoptosis of perifollicular lymphocytes. Eur J Dermatol 16: 537-542. [Crossref]

2. Avgerinou G, Gregoriou S, Rigopoulos D, Stratigos A, Kalogeromitros D, et al. (2008) Alopecia areata: topical immunotherapy treatment with diphencyprone. $J$ Eur Acad Dermatol Venereol 22: 320-323. [Crossref]

3. Krüger C, Schallreuter KU (2012) A review of the worldwide prevalence of vitiligo in children/adolescents and adults. Int J Dermatol 51: 1206-1212. [Crossref]

4. van den Boorn JG, Konijnenberg D, Dellemijn TA, van der Veen JP, Bos JD, et al. (2009) Autoimmune destruction of skin melanocytes by perilesional $\mathrm{T}$ cells from vitiligo patients. J Invest Dermatol 129: 2220-2232. [Crossref]

5. Toosi S, Orlow SJ, Manga P (2012) Vitiligo-inducing phenols activate the unfolded protein response in melanocytes resulting in upregulation of IL6 and IL8. J Invest Dermatol 132: 2601-2609. [Crossref]

6. Van der Veen JP, Yazdani M (2012) Pigment disorders. Kanerva's Occupational Dermatology, (2ndedtn). Springer Verlag, Berlin: 285-293.

7. Pan JY, Theng C, Lee J, Goh BK (2009) Vitiligo as an adverse reaction to topical diphencyprone. Ann Acad Med Singapore 38: 276-277. [Crossref]

8. Ganzetti G, Simonetti O, Campanati A, Giuliodori K, Offidani A (2010) Phototherapy as a useful therapeutic option in the treatment of diphenylcyclopropenone-induced vitiligo. Acta Derm Venereol 90: 642-643. [Crossref]

9. Pires MC, Martins JM, Montealegre F, Gatti FR (2010) Vitiligo after diphencyprone for alopecia areata. Dermatol Res Pract 2010: 171265. [Crossref]

10. Daniel BS, Wittal R (2015) Vitiligo treatment update. Australas J Dermatol 56: 85-92. [Crossref]

Copyright: (C2015 Quaresma MV. This is an open-access article distributed under the terms of the Creative Commons Attribution License, which permits unrestricted use, distribution, and reproduction in any medium, provided the original author and source are credited. 